\title{
Tillgång till offentligheten: synlikhet och rörlikhet Muslimska kvinnors religiösa aktivism i Istanbul
}

Af Catharina Raudvere

Politisk religiøs uddannelse for tyrkiske kvinder $i$ Istanbul byder bàde på Foucault, Habermas såvel som Kovanlesning. Men giver det politiske handlerum øgede muligheder for kvinder eller indeholder politiseringen af Islam nye begransninger?

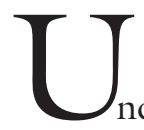

nder ett fältarbete $\mathrm{i}$

Turkiet befann jag mig en dag i en mötesplats för kvinnor i Istanbuls utkanter. Det var en enkel, men välkänd, föreningslokal som användes för kvinnors religiösa utbildning. Rummet var tämligen fattigt på möbler, men hade ändå en mycket speciell karaktär. Ena väggen var täckt med religiösa dekorationer från pilgrimsresor till Mecka och med statusgåvor från utvandrade släktingar i Tyskland och Holland. Den andra väggen var täckt med bokhyllor. Där fanns hela Koraner, instuderingshäften med enstaka suror på arabiska och i turkisk översättning, bönböcker, predikosamlingar och uppbyggelselitteratur som användes för undervisning i lokalen. Men på hyllorna stod också litteratur från kurser på universitetet. Här trängdes titlar av Foucault, Habermas och Sontag tillsammans med mer konventionella läroböcker i historia och sociologi.

Ett bönemöte av mycket intensiv karaktär var nyss avslutat och kvinnorna som hade deltagit kopplade av med te och småprat 
i ett angränsande rum. Några flockades kring böneledaren, en kvinna i 60-årsåldern, för att fråga henne till råds $\mathrm{i}$ mer privata angelägenheter. Men veckans stora diskussionsämne, bland de andra kvinnorna och i hela Turkiet, var det förestående åtalet mot Istanbuls islamistiske borgmästare Tayyıp Erdogan och de dagliga demonstrationer som arrangerades till hans försvar. Samtidigt som diskussionerna pågick klickade en tonårsflicka med fjärrkontrollen mellan den islamistiska TV-stationen Kanal 7 och Kral (det turkiska svaret på MTV) där en Madonnavideo visades. Flickan sjöng med en stund och zappade sedan vidare och skärmen visade oss en sekvens från en tjetjenisk sharia-rättegång som det statliga TV-bolaget visade om och om igen i sina nyhetssändningar den veckan.

Blandningen av politiska frågor, intensiva böner, popmusik och socialt nätverksskapande tillsammans med den lätthet med vilken kvinnorna rörde sig mellan de olika frågorna - allt medan de planerade nya koranlektioner, matdistribution till de fattiga och spred information om nya demonstrationer - verkade inte bekymra någon annan än mig, den essäskrivande gästen. Flödet av information, idéer, ljud och bilder var uppenbarligen en självklar del av kvinnornas vardag.

Just det här mötet ägde rum på våren 1997 och var en påtaglig blandning av både det hävdvunna och nydaning. På vad sätt hade scenen varit annorlunda tjugo år tidigare? Sammankomster för bön och gemenskap i enkönade rum, upprättade efter särhållandets princip, fanns definitivt sedan generationer, framför allt i privata miljöer. Men andra aspekter var nya sedan mitten av 1980-talet: fromma kvinnor som reser över megastaden för att kunna delta i möten av det slag de själva valt. Närvaron av en politisk debatt under kvinnors religiösa möten är också ny. Den kanske allra viktigast nydaningen är att religiösa kvinnors aktivism kan ha ett direkt lokalt inflytande utanför de politiska och administrativa organisatio- nerna. De aktivistiska muslimska kvinnogrupperna är inte någon isolerad företeelse, utan utgör delar av det spektrum av NGO:s som utmanar den statscentralism som utmärkt med turkiska sekularismen sedan Atatürks dagar (Göle 1996a, Davison 1998). Om man betänker att gruppen som beskrevs ovan inte är unik som "gräsrotsrörelse" - det finns många kvinnogrupper av det här slaget i Istanbul, i Turkiet (Saktanber 1994, Göle 1996b, Toprak 1996, Raudvere 1998) och i hela den muslimska världen - så kan inte deras inflytande sägas vara begränsat. De kvinnogrupper som verkar i den aktuella stadsdelen är långt ifrån förenade var sig i värderingar eller metoder att agera, men var och en lämnar de ett avtryck i sitt lokala sammanhang. Teorier om globalisering och det senmoderna samhället borde kunna kasta ljus på dessa kvinnors liv och deras aktiviteter. I en miljön som den ovan beskrivna flyter världen oavbrutet in via nya medier, och reaktionerna på det globala flödet uttrycker en reflekterad hållning.

Begreppet globalisering används så flitigt både $\mathrm{i}$ massmedia och inom akademin att det finns skäl att fråga om ordet används för att karaktärisera en socioekonomisk förändring eller om det är politisk retorik. Men andra ord: Är det ett analytiskt begrepp eller en mångtydig metafor för att prisa eller avfärda en världsomspännande fri marknadsekonomi (Scott 1997). Man bör även ställa frågor om var globaliseringen äger rum och inte bara studera vad som är produkter av globaliseringen utan även ge exempel på småskaliga aktiviteter som driver globaliseringen på ett lokalt plan (Rosenneil 1997:5).

Under mitten av 1990-talet följde jag en liten lokal muslimsk kvinnogrupp och deras aktiviteter i centrala Istanbul under några år ${ }^{1}$. Kvinnorna arrangerar egna bönemöten och koranundervisning, men är även som grupp involverade i mer socialt inriktade välfärdsprojekt till förmån för andra kvinnor i grannskapet. Gruppen består av en in- 
re cirkel av ett tiotal kvinnor som med sina olika program når cirka 150 kvinnor $\mathrm{i}$ veckan. Några av de ledande har universitetsutbildning, men deras främsta målgrupp är kvinnor från den lägre medelklassen. Intensiteten är stor hos dem som bidrar på olika sätt och hänvisningar tradition och historiska modeller far ofta genom luften i diskussioner och i planering av ny verksamhet. Kvinnorna etablerade under fältarbetets gång en stiftelse (vakıf) för att i större skala kunna arrangera bönemöten, grundläggande religiös utbildning och välgörenhet. Organisationsformen som sådan har varit av största betydelse för arbetets omfång. Stiftelsen skänker oberoende för kvinnorna gentemot (manliga) familjemedlemmar och gentemot andra lokala religiösa institutioner. Men de kan också genom stiftelsen ackumulera kapital för att investera både kulturellt och rent monetärt i nya och mer storskaliga projekt. Kvinnorna i stiftelsen är lokalt välkända, inte bara på grund av arten av aktiviteter, utan också intensiteten och effektiviteten. Sedan det första preliminära fältarbetet i början på 1990-talet har en uppenbar formaliseringsprocess ägt rum. Dessa kvinnor har tagit flera steg från mer privata sfärer ut $\mathrm{i}$ offentligheten och en större synlighet. Termen vakıf avser i kvinnornas vardagsspråk både organisationen och mötesplatsen. De har skapat egna rum som är garanterat anständiga att vistas i och de har skapat ett specifikt rum för bön på de tider de själva väljer och under villkor de själva formulerar. Allt vad som sker i lokalen bedöms utifrån religiöst bestämda parametrar som anständighet och renhet. Men gruppen tänjer också hela tiden gränserna inom den givna muslimska ramen för vad religiösa kvinnor anses vara kapabla att göra. Med kvinnliga dygder och respektabilitet som argument har de uppnått friheter, både teologiskt och socialt, under de senaste åren.

Alltför ofta beskrivs kvinnor i "tredje världen" eller outbildade kvinnor i "Västerlandet" som offer när man talar om fe- nomen som globalisering och urbanisering. Med en beklagande underton framställs kvinnorna som "drabbade" av olika stora processer. Ambitionen med projektet har varit att visa att kvinnor utanför det som slentrianmässigt definieras som västerlandet också tar aktiv del av dessa processer och att de inte kan framställas som determinerade av sin fattigdom, sitt kön eller sin religion. De bejakar eller protesterar, men de är inte passiva. De väljer inte heller alltid de förväntade kommunikationssätten, utan nya arenor att framföra sina åsikter på. Det kan därför vara ett rent praktiskt problem att finna de nya kvinnogrupperna $i$ städernas utkanter och samla in information.

\section{MED HISTORIEN SOM SPEGEL OCH FRAMTIDEN SOM MÅL}

Det har varit en självklar utgångspunkt $\mathrm{i}$ studien att betrakta kvinnorna som en del av det moderna Turkiet, även om de aldrig själva skulle beteckna sig med sådana termer. I min förståelse är moderniteten som socialt och politiskt tillstånd själva förutsättningen för både arten och graden av aktivism. "Modern" är däremot i deras språkbruk en retorisk figur som man använder om sina främsta ideologiska motståndare: representanter för det sekulära turkiska majoritetssamhället. För dem är modern en pejorativ term som representerar samtidens värsta avarter. De betraktar sig själva som "återvändande" - inte bara till islam, utan även till ett uråldrigt nationellt arv. Islams nya synlighet $\mathrm{i}$ det turkiska samhället kan aldrig förstås utan dess ofta mycket hårdföra nationalistiska accent. Den hävdvunna traditionen är visserligen förödd av den västerländskt styrda sekularismen, men kvinnorna i studien ser sin uppgift att vägleda sina samtida systrar mot ett återupprättande av denna historiska utopi. De ser sig som förvaltare av traditionen med versaler och den är för dem muslimsk, turkisk och enhetlig. Det man åstadkommer är alltså 


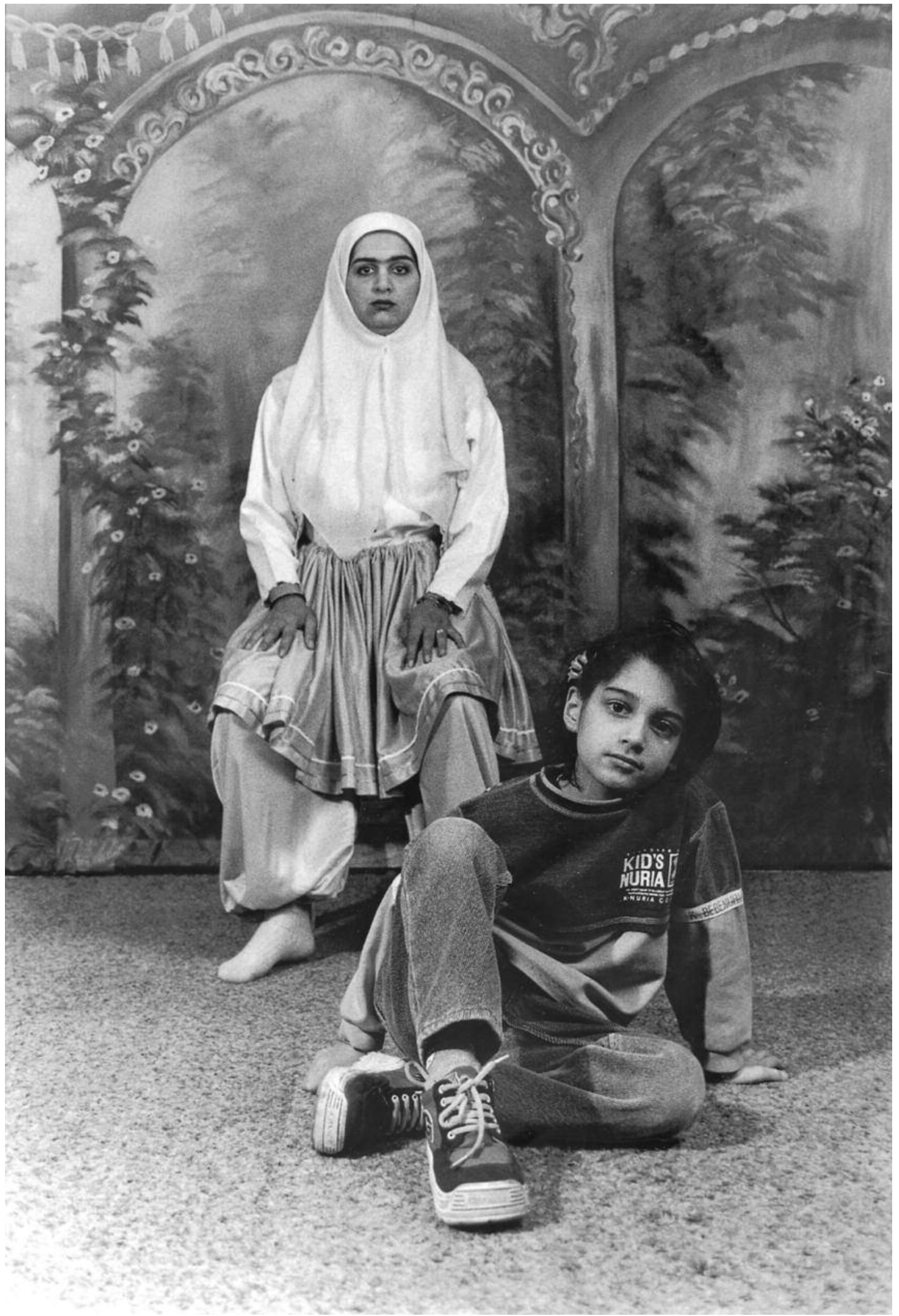


inte definierat som en nydaning, utan steg på vägen mot ett förverkligande av en historisk utopi. En individ i deras omvärld är alltid innanför eller utanför och därför blir också aktivismen intensivt missionerande och absolut exkluderande gentemot dem som ställer sig tveksamma till det islamistiska samhällsprojektet. Strävan att lösa sin samtids problem genom att hänvisa till traditionen är inte något specifikt muslimsk fenomen eller kopplat till någon särskild religion. Snarare är det många gånger rimligt att tolka referenser till religion och lokal kultur som en anti-kolonial diskurs, riktad mot en diffust definierad västerländsk kulturell hegemoni. Sett ur ett kvinnoperspektiv kan man dock notera att den nya betoningen av tradition många gånger innebär att ett begränsande värdesystem byts mot ett annat.

Kvinnornas budskap förordar ett återvändande till källorna: till Koranen och till haditherna (de första muslimernas normerande beteende) och ett liv som islams pionjärer. Denna hållning länkar dem till den bredare islamistiska rörelsen som hyllar bilden av salaf, de första tre generationerna av troende muslimer som för dem representerar "autentisk" teologi och praktik. Trots att dessa föregångare ovedersägligen var araber finns det inga hinder att integrera berättelserna om den i en mer nationalistiskt färgad religiös diskurs. I sitt avståndstagande från den rådande tidsandan bygger kvinnorna $\mathrm{i}$ vakıf sin världsbild från en dubbel historisk utopi: Medinamodellen från de heliga skrifterna och föreställningar om osmanskt liv före republikens grundande.

Själva organiserar kvinnorna sina aktiviteter efter vad de uppfattar som osmanska ideal. Den förrepublikanska eras enorma moskékomplex med alla dess religiösa och sociala institutioner (själva moskén och andra böneplatser, heliga gravar, bibliotek och utbildningsanstalter, matbespisning till de fattiga, sjukhus m.m.) utgjorde ett nav i det lokala livet som i dag ter sig eftersträvansvärt. Med denna historiska spegel för ögo- nen undervisar de, predikar, hjälper, vårdar och mättar; alltså sådan verksamhet som brukar tillskrivas civilsamhället. Dessa aktiviteter är anti-moderna i kvinnornas egen förståelse och, som de själva ser det, del av ett kulturellt och politiskt motstånd. Med mina glasögon är både kvinnorna och deras organisation i allra högsta grad ett fenomen i det senmoderna samhället.

När Alberto Melucci karakteriserar dagens sociala rörelser kallar han dem "nomader i nuet" (Melucci 1992). Han påpekar att de i sig inte upphäver andra samhälleliga kategoriseringar utan snarare samexisterar med dem. Istället är grupperna många gånger tillfälliga eller inriktade på en specifik fråga och verkar många gånger utanför de traditionella politiska organisationerna. Därför kan de inte heller alltid skrivas in på en höger/vänsterskala. När han skriver: "I de komplexa samhällena utvecklas konflikter inom de systemdelar som är centrala för produktionen av information och symbolresurser, och som samtidigt står under det största konformitetstrycket" (Melucci 1992:68) är det en adekvat beskrivning av den uppslitande och ständigt återkommande debatt huvuddukarnas närvaro på universiteten skapat.

\section{PARADOXER}

Jämfört med kvinnors religiösa aktiviteter i Turkiet för 20 år sedan är kvinnornas i stiftelsen inte bara mer storskaliga och offentliga, utan i allra högsta grad också del av globala skeenden. Om man vill försöka förklara vad som är tradition eller innovation, globalt eller lokalt hamnar man ofta i paradoxer. $\AA$ ena sidan finns i dagens Turkiet fler religiösa valmöjligheter än någonsin. En uppenbar individualisering har ägt rum i den mening att det personliga valet poängteras även bland fattiga och outbildade kvinnor. $\AA$ andra sidan är det dom de numera så synliga religiösa grupperna lär ut många gånger en auktoritär, mer eller mindre radikal, islamistisk universalism. 
Att beskriva förhållandet mellan sekularism och de senaste årtiondenas muslimska rörelser är en historia av paradoxer. Många konventionella sekulariseringsteorier betonar kraftfullt starkt privatiseringens koppling till moderniteten, något som motsägs av materialet från min studie (Casanova 1994:35ff). Ofta finns en implicit spatial förståelse av

I det turkiska fallet har det varit statsmakternas ambition att reglera den offentliga religionsutövningen till de av byråkratin kontrollerade moskéerna. Genom ministeriet för religiösa angelägenheter både organiserar och kontrollerar staten en stor del av de muslimska kollektiva religiösa aktiviteterna. Formellt sett ska större muslimska sammankomster äga rum i offentliga lokaler, det vill säga i de flesta fall moskén. Ministeriets definitioner marginaliserar därmed i hög utsträckning kvinnors verksamhet (som, hur den än gestaltas, kommer att räknas som "privat" eftersom den inte ingår i moské-imamparadigmet) liksom ministeriet marginaliserar alla de grupper som inte räknas in bland de traditionellt sunnimuslimska.

Turkiska kvinnors religionsutövning har alltid varit privat i spatial bemärkelse. Det är först under de senaste decennierna muslimska kvinnor, till följd av sociala, politiska och tekniska förändringar, börjat använda sig av offentligheten. Men några enkla motsatspar som offentligt - privat kopplat till manligt - kvinnligt står inte att finna. Den explosionsartade urbaniseringen har skapat nya familjestrukturer som innebär att många kvinnor förvärvsarbetar. Även de mest fromma kvinnor som vill upprätthålla den rumsliga separationen mellan kvinnor och män måste röra sig över stora ytor i det urbana landskapet: de syns och de ser.

Den enklaste, men många gånger mest effektiva, demonstrationen för de religiösas närvaro på alla nivåer i samhället är klädseln (Özdalga 1998). Valet av kläder för både män och kvinnor utgör läsbara koder i stadsbilden. De är markörer som omedel- bart signalerar den religiösa hemvisten. Även den mest inbitne kemalist har måst inse att "de religiösa” absolut inte är någon enhetlig kategori eller kan avfärdas som outbildade lantbor.

Religionens roll i det turkiska 1900-talssamhället har varit långt ifrån entydig. Kemalismen har av omvärlden betraktats som religionsfientlig, men har en kluven hållning till Turkiets muslimska historia. Den representerar såväl det förmoderna och rationella som kulturskatter och nationell särart.

\section{RÖRLIGHET:}

NYA RUM OCH NYA PLATSER

Förändringarna i kvinnors religiösa arenor har många gånger en krass ekonomisk bakgrund. Urbaniseringen har lett till att allt fler kvinnor rör sig i främmande miljöer och att en växande medelklass har ekonomiska möjligheter att investera i religiös status. Det är också enskilda familjers förmögenheter (i flera fall tillkomna under arbetsmigration) som utgör grunden till kvinnornas avancerade välgörenhetsprogram. Med sin stiftelse, vakif, har gruppen skapat ett eget rum som uppfyller Virignia Woolfs klassiska kriterium "money and a room of one's own". De har upprättat både "space” och "place” (Raudvere 1999).

Genom sin mötesplats har kvinnorna, utan att det explicit formuleras som en explicit målsättning, omdefinierat villkoren för lokal religiös aktivism. Förändringarna gäller inte bara sättet att agera i vardagen, utan även förmedlingen av kunskaper om historien, tradition och samtida muslimska angelägenheter.

Men det är inte bara världen som flyter in till vakıf. Kvinnorna beger sig själva ut i världen, med bevarad heder och anständighet. Arbetsmigrationen är vid sidan av massmedierna kanske den viktigaste faktorn vad gäller bilder av världen. Den har givit många kvinnor erfarenheter både genom egna vistelser och genom kontakter med emi- 
granter. Men även stiftelsens verksamhet bidrar aktivt till nya kunskaper.

Ett av de mer frappanta exemplen på kvinnors nya rörlighet och synlighet är de många hac-resor till Mecka kvinnorna i studien har arrangerat en gång om året under en följd av år. Länge var hemmiljön, bland nära släktingar och vänner, den givna arenan för kvinnors kollektiva religiösa aktiviteter. Den lokala moskén har sällan varit kvinnors plats. Få kvinnor gav sig ut på resa $\mathrm{i}$ fromma angelägenheter och än färre vallfärdade till Mecka. För de allra flesta kvinnor var ett besök vid en helgongrav (zaviye) under en kortare pilgrimsresa det enda tillfället då de utnyttjade offentliga rum av uteslutande religiös karaktär.

En utlandsresa är endast tänkbar för fromma kvinnor tillsammans med en grupp som är välkända för det att de följer moralregler (edep) och koden för korrekt klädsel (tesettür) och det har gällt för de ledande kvinnorna inom vakıf att balansera önskan om att låta så många kvinnor som möjligt resa mot gränsdragningen för vad en familjeflicka eller mor kan tillåtas göra.

Resorna till Mecka är organiserade på charterbasis och en researrangör tar hand om alla tekniska och administrativa förberedelser. Men det är stiftelsen tar initiativet till dessa resor framstår som en möjlighet och väcker tanken om att en resa till Mecka är möjlig även för mindre bemedlade kvinnor. Medlemmar ur gruppen hjälper även till med de mer praktiska råd om hur man kan ekonomiskt stöd och delar med sig av egna erfarenheter om de ceremonier som väntar under resan.

Men pilgrimsresan som tillfälle till internationella kontakter ska inte överdrivas. Det finns ingen absolut korrelation mellan att resa och att verkligen träffas. Av diskussionerna efter hemkomsten framgår det att kvinnorna i stor utsträckning håller sig för sig själva under vistelsen i Saudi Arabien och mer djupgående kontakter med muslimer från andra länder är ovanliga. När det bilden av den internationella muslimska kommuniteten (ümmet) är Meckaresornas betydelse är av ett annat slag. De återvändande kvinnornas uppfattningen om "de andra muslimerna" bygger i hög utsträckning på synintryck och deras minnen återberättas under lång tid inom gruppen. När televisionen visar scener med muslimer i Indonesien eller Afrika börjar de som varit på pilgrimsresa att referera till sina observationer $\mathrm{i}$ Mecka och Medina och pilgrimsresan utvecklas till en kollektiv internationell erfarenhet. Minnena förvaltas gemensamt och ganska snart tappar berättelserna uppgifter om vem som var ögonvittne till det skedda.

De minnen kvinnorna för hem återberättas även i grannskapet och stöttar gruppens status. Att hjälpa en annan människa att uppfylla plikten att göra en resa till Mecka har traditionellt alltid ansetts vara en religiös merit. Både avfärd och hemkomst är föremål : vem som har åkt, vem som fick vad av vem. Från tiden i Saudi Arabien vandrar också historier: mirakler om hur vänner hittar varandra i de stora folksamlingarna, bönesvar i Mecka, ord från Koranen som plötsligt från en ny mening och tolkas som lösning på problem etc. Vallfärdshistorierna berättas om och om igen och blir till slut en del av gruppens sociala minne och förbinder denna lilla grupp med alla muslimers universella centrum. Upplevelserna i Mecka, egna eller andras, tas ofta upp som kommentar till nyheter från den muslimska världen. Det senmoderna samhället beskrivs ofta som flerpolär och Mecka hör i dubbel mening hemma bland de platser som tävlar om global signifikans. Inom den islamistiska diskursen är Mecka ett alternativ till den västerländska hegemonin och i Mellan Österns politiska kontext minskar detta kulturella nav betydelsen av nationalstaterna. Båda aspekterna är påtagliga i dagens Turkiet. "Den nya religiösa medvetenheten", med alla sina inre motsättningar, förenas av en vag, men högljudd, retorik mot "väst". Den får sällan några praktiska konsekvenser, men dess strävan är att inkorporera hela den muslimska gemenskapen (ümmet) i 
återvändandet till “det trogna Medina” där Muhammeds idealsamhället tänks ha varit verklighet.

Vallfartsresorna har alltså inte betydelse endast för dem som verkligen reser. Den enskilde resenären delar sina erfarenheter med familj, vänner och grupper hon är associerad med. Hemkomstmottagningen är en minst lika viktig del av hac som själva utlandsvistelsen. Pilgrimen, hacı, välkomnas tillbaka bland dem som bett för resenären under hennes bortovaro, mottagit telefonrapporter och följt vännerna genom de dagliga TV-sändningarna under vallfartsmånaden. Telekommunikationen făr både personlig och mer allmänreligiös betydelse och upphäver känslan av "här” och “där”.

Minnena från pilgrimsresan är inte enbart verbala, utan i lika hög utsträckning påtagliga objekt. Flödet av konsumtionsvaror är alltid något som betonas $\mathrm{i}$ globaliseringsteorier och i den studerade gruppen är föremål en väsentlig del av det symboliska universum som stiftelsen kontinuerligt bygger upp. Det är lätt att avfärda souvenirerna som krimskrams eftersom de ofta är masstillverkade i Kina eller Malaysia. Det rör sig om gestaltningar av Kaba och profetens moské i alla tänkbara former och material: kalligrafiska plattor att sätta på väggen eller shopping-väskor med namnet Medina broderat. Men hac-gåvorna har en stor betydelse vad gäller att etablera och upprätthålla sociala kontakter. Akterna att ge och motta är tämligen formaliserade och genomförs vid de mottagningar som arrangeras inom några dagar efter hemkomsten. Att ge är ett sätt att visa mottagaren respekt och att överföra välsignelse (bereket) från en plats till en annan. Det samma sker med det zemzem-vatten som förs hem i stora mängder i återbrukade 5-liters flaskor. Det välsignande vattnet delas ut så länge det räcker som slutceremoni under gruppens bönemöten. Vattnet serveras i teglas från en bricka och kvinnorna reser sig från bönecirkeln och vänder unisont ansiktet mot Mecka. Efter en gemensam bön sväljes vatt- net i en klunk. Så upprättas den fysiskt påtagliga kopplingen mellan den muslimska världens centrum och en kvarterslokal för bön och undervisning.

Dessa tillsynes banala objekt (inramade bilder, pennor, portmonnäer etc.) är laddade med social och religiös mening. De personliga gåvorna fungerar som påtagliga bevis för vänskap och bekräftar sociala och emotionella band mellan två kvinnor. Mottagarens status är också påverkad. Vidare säljer gruppen ting från Mecka och Medina som ska dra in pengar till verksamheten. Man arrangerar långa bord med egentillverkade bruksföremål och i mitten tronar souvenirerna från Mecka. Även under en sådan försäljning (kermes) de till synes obetydliga föremålen som en effektiv legitimitetsmarkör för kvinnornas vidare verksamhet.

\section{BEGRÄNSNINGAR OCH MÖJLIGHETER}

Det har inte varit min mening att reducera de resonemang som driver kvinnorna till politiska skeenden, globala eller nationella. Det finns en påtaglig risk att analyser av islamisk aktivism reduceras till en fråga om politik och att de religiösa dimensionerna för de enskilda individerna försvinner. Därför uppskattar jag Alberto Meluccis strävan att integrera individuella behov $\mathrm{i}$ analysen av sociala rörelser i komplexa samhällen. Han skriver: "Det finns hos de sociala fenomenen dimensioner - till exempel affektiva eller symboliska relationer - som inte kan betraktas som politiska emedan de fungerar efter en annorlunda logik, som det därför är nödvändigt att respektera och inte kränka" (1991:173). Jag hyser en djup beundran för vad kvinnorna i studien åstadkommer i sin välgörenhetsverksamhet, samtidigt som båda parter är medvetna om att våra grundläggande värderingar är olika.

Den moderna världen innebär inte traditionens död, utan snarare möjlighet att välja bland traditioner. Detta val sker oftast inom ramen för en bestämd diskurs, som i detta fall den turkiska islamistiska. I akade- 
miska diskussioner om modernitet är nyckelord som subjekt och reflexivitet vanliga, men många rörelser i det moderna rör sig inom auktoritära diskurser. Valen som måste träffas innebär mycket konkret både möjligheter och risker för stiftelsen driver på en ständig reflexion hur långt kan kvinnorna gå i sina ambitioner.

I en turkisk kontext verkar de olika NGO:s, religiösa eller inte, i frihetszoner som tidigare inte fanns. Men genom sin aktivism provocerar de fram nya begränsningar - inte bara från statens sida utan i allra högsta grad inom grupperna. Det gäller att “reglera komplexiteten" som Alberto Melucci skriver (1992:171).

\section{Note}

1. Projektet finansierades av Humanistiska-samhällsvetenskapliga forskningsrådet. Resultaten kommer att redovisas i monografin "Under my sisters' protection": Sufism and zikir among women in contemporary Istanbul.

\section{LITTERATUR}

- Beyer, Peter. 1994. Religion and Globalization. London.

- Casanova, José. 1994. Private and public religions in the modern world. Chicago and London.

- Davison, Andrew. 1998. Secuarism Revivalism in Turkey. New Haven \& London.

- Delaney, Carol. 1990. "The Hac: Sacred and Secular." American Ethnologist 17:513-530.

. Göle, Nilüfer. 1996a. The forbidden modern. Civilization and veiling, Ann Arbor.

- 1996b. "Authoritarian secularism and islamist politics: the case of Turkey" in: Civil society in the Middle East vol. 2 Augustus Richard Norton (ed.) Leiden.
- Melucci, Alberto. 1989. Nomads of the present social movements and individual needs in contemporary society, London.

- Metcalf, Barbara. 1996."Introduction: sacred words, sanctioned practice, new communities" in: Making Muslim space in North America and Europe Barbara Metcalf (ed.) Berkeley.

- Raudvere, Catharina.1998. "Urban Visions and Religious Communities: Access and Visibility" In Alevi Identity: Cultural, Religious and Social Perspectives Tord Olsson, Elisabeth Özdalga \& Catharina Raudvere (eds). Istanbul.

- Robertson, Robert. 1992. Globalization: Social Theory and Global Culture. London.

- Roseneil, Sasha.1997. "Contesting Global Forces" In The Limits of Globalization Alan Scott (ed.). London.

- Saktanber, Ayse. 1994. "Becoming the "other" as a Muslim in Turkey: Turkish women vs Islamist women" New perspectives on Turkey vol. 11, pp 99. 134.

- Scot, Alan. 1997. "Introduction: Globalization Social Process or Political Rhetoric?" In The Limits of Globalization Alan Scott (ed.). London.

. Toprak, Binnaz. 1996. "Civil society in Turkey" in: Civil society in the Middle East vol. 2 Augustus Richard Norton (ed.), Leiden.

. Özdalga, Elisabeth 1998. The veiling issue. Official secularism and popular Islam in modern Turkey. London.

\section{SUMMARY:}

The article discusses muslim women and religious practices in Istanbul, Turkey. By using theories of globalization and the post-modern society, the author analyzes the possibilities in the politization of Islam for the active Muslim women as a way to become part of the social development.

Catharina Raudvere er docent på Teologiska Institutionen, Islamologi, Lunds Universitet 